\section{UN TALLER IBÉRICO DE TRATAMIENTO DE LINO EN EL COLL DEL MORO DE GANDESA (TARRAGONA)}

\author{
AN IBERIAN TEXTIL WORKSHOP AT \\ COLL DEL MORO DE GANDESA \\ (TARRAGONA)
}

\author{
NÚRIA RAFEL I FONTANALS (*) \\ MÒNICA BLASCO I ARASANZ (**) \\ JORDINA SALES I CARBONELL (***)
}

\section{RESUMEN}

Se presentan los resultados de la excavación de un conjunto arquitectónico de la segunda mitad del siglo III a.C. compuesto por dos estancias que se comunican con una de las torres del recinto fortificado. En una de dichas estancias se han documentado dos depósitos impermeabilizados y estancos donde se procedía al enriado de la planta del lino para extraer la fibra.

\begin{abstract}
This article deals with an architectural complex, dated to the second half of the third century b.C., which is composed of two rooms that comunicate with one of the towers of the settlement wall. In one of them there were excavated two waterproof deposits, which provided evidence of the production of linen from flax.
\end{abstract}

Palabras clave: Cultura ibérica. Tejido. Telar. Taller de lino. Fortificaciones. $2^{\text {a }}$ Guerra Púnica. Lleida

(*) Universidad de Lleida. Rambla d’Aragó 37. 25003

(**) Bailén $95-97,4^{\circ} 2^{*} .08009$ Barcelona.

(***) Custiol 5, 4\%.08700 Igualada.

Este artículo fue remitido en su versión final el 10-VI-94.
Key words: Iberian culture. Woven. Loom. Linen Workshop. Fortifications. Second Punic War.

El área arqueológica del Coll del Moro está ubicada sobre una serie de pequeñas elevaciones montañosas del término municipal de Gandesa (Terra Alta, provincia de Tarragona), a unos $6 \mathrm{Km}$. al oeste de la población y al pie de la carretera que la une con Calaceite, ya en la provincia de Teruel. El yacimiento comprende una extensa necrópolis de incineración tumular, con tres sectores diferenciados, que se encuadra cronológicamente entre el 800 a.C. y el siglo IV a.C. (Molas, Rafel y Puig, 1986a, b; Rafel, 1989, 1991, 1993; Rafel y Hernández, 1992) y un poblado fortificado situado a $1 \mathrm{Km}$. escaso de las zonas sepulcrales, protegido en la parte alta por una gran torre de planta elipsoidal, exterior y avanzada respecto al recinto amurallado, que está además asociada a un conjunto de estructuras de notable complejidad entre las cuales destaca un foso. Detrás de la torre se halla el poblado, asentado en la pendiente de un espolón y defendido por una muralla, de la cual se cono- 


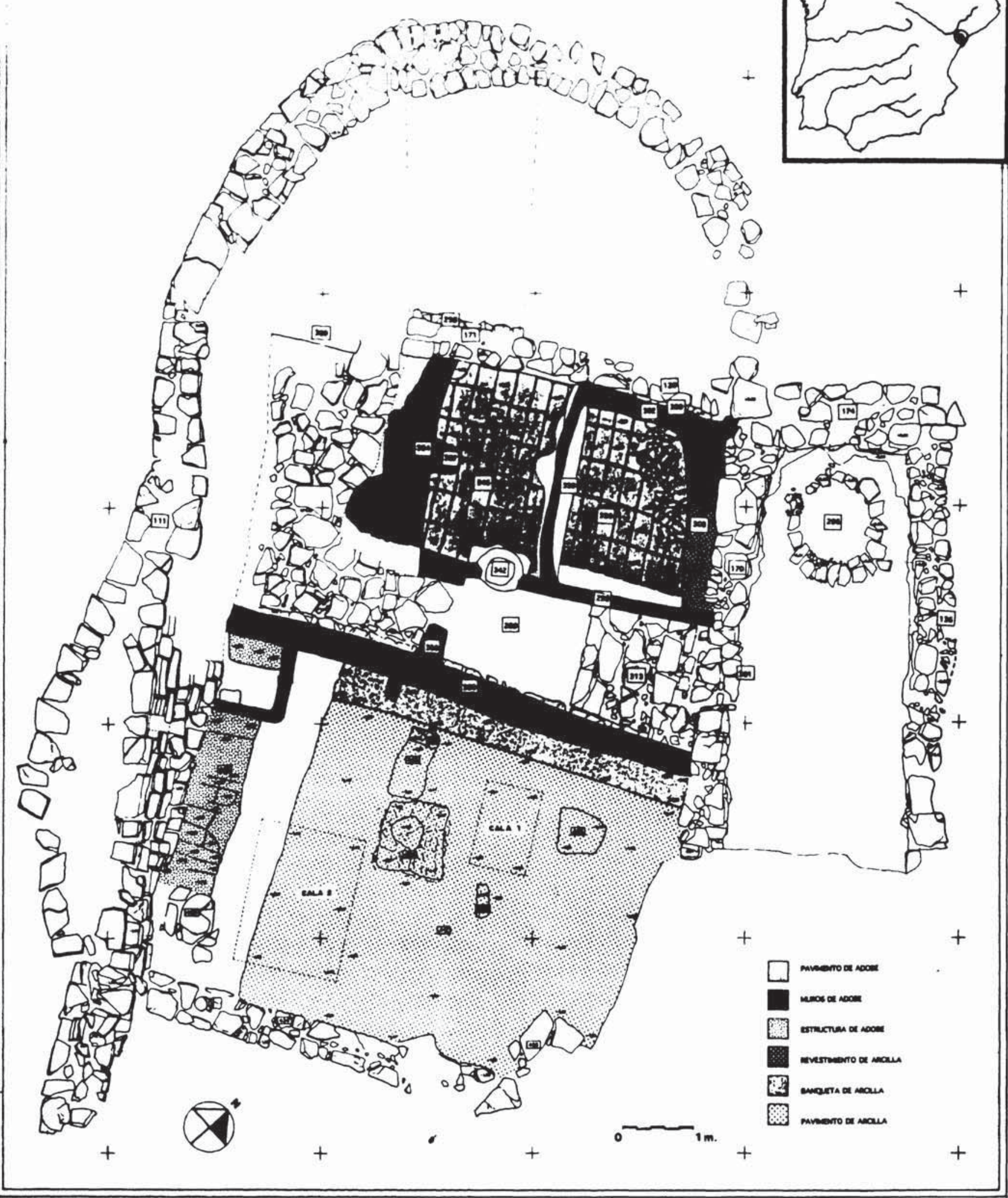

Fig. 1. Localización del yacimiento en la Península Ibérica y planta general del taller y la torre. 
cen tres torres semicirculares unidas por lienzus rectilineos (Berges y Ferrer. 1976: Rafel y Puig, 1985: Rafel y Blasco, 1991).

Las excavaciones realizadas hasta el momento han centrado su atención en el conocimiento de las estructuras defensivas de la zona alta del asentamiento, de manera que el interior del poblado todavía no ha podido ser estudiado. Las estructuras más antiguas son la torre y el foso, que corresponden a principios del s. V a.C., mientras que la muralla del poblado se fecha provisionalmente en la segunda mitad del s. III a.C. Los niveles más tardíos del yacimiento han sido muy destruidos a causa de los trabajos agrícolas, pero hay indicios de ocupación hasta el altoimperio (Rafel y Blasco, 1991; 1994).

El desarrollo y consolidación del poblamiento en el Coll del Moro se debió en gran parte a su emplazamiento geográfico (Fig. 1), en un punto neurálgico de las vías de comunicación que unen la desembocadura del Ebro y litoral próximo con el Bajo Aragón y los valles del Segre y del Cinca, situación que le habría permitido integrarse, y quizás también controlar, los flujos de intercambio entre la costa y el interior, activos al menos desde la segunda mitad del siglo VII a.C. (Rafel, 1989: 19-26, 31-34).

Las recientes excavaciones realizadas en el poblado han puesto al descubierto, en un excepcional estado de conservación, tres ámbitos interconectados que han sido identificados como una instalación destinada al tratamiento del lino y a la manufactura de tejidos. El taller se ha localizado en el ángulo noroccidental del recinto fortificado, adosado a la cara interna de las murallas. La pieza principal y central del complejo es una habitación cuadrangular (ámbito 7) que contiene dos depósitos rectangulares y simétricos adosados a una de sus esquinas, mientras que el resto de la estancia está libre de estructuras a excepción de un cuerpo de escaleras por las cuales, y a través de una puerta, se accede a la pieza contigua por el Este (ámbito 6 ), que presenta un hogar de dimensiones considerables en la cabecera. También desde el ámbito de los depósitos, pero por el extremo opuesto, se accede al interior de la torre noroccidental del recinto fortificado, a través de una puerta practicada en el muro rectilíneo que la cierra por el sur. de manera que queda integrada en la misma unidad estructural.

Tanto la morfología de los depósitos, cuidadosamente impermeabilizados con arcilla, como sobre todo los análisis realizados de los sedimentos localizados en su interior (ver Anexo), permiten afirmar que habian contenido gran cantidad de lino en maceración. proceso que constituye uno de los primeros pasos en la transformación de esta planta en materia apta para ser tejida. Por cuanto atañe a la torre, el sondeo practicado en su interior proporcionó una notable cantidad de tinajas y grandes recipientes, enteros aunque muy fragmentados, que hacen plausible suponer la existencia de un almacén. Por otro lado, el hogar situado en el ámbito 6 , sin ningún indicio fehaciente de actividad estricta y exclusivamente doméstica, podría estar vinculado también al mencionado proceso de transformación del lino. No podemos excluir, sin embargo. la posibilidad de que se realizaran otras actividades y operaciones, algunas de ellas relacionadas con la actividad textil. Efectivamente, la exhumación de 107 pondera en los estratos de derrumbe de la superestructura del ámbito 7 permiten considerar no sólo la preparación de la materia prima sino también la posterior manufactura de tejidos.

El objetivo del artículo es la presentación de este conjunto en el momento en que fue utilizado como taller textil (las posteriores reutilizaciones documentadas no tenían ya esta función). Hemos creído de interés ofrecer un avance de la publicación de conjunto en curso de elaboración por el carácter singular de los restos que nos ocupan. Aunque ya desde el Calcolítico se procesaba el lino para uso textil, posiblemente en agua corriente, como permiten suponer los hallazgos de lino de dicho período en la Península Ibérica, los restos del Coll del Moro constituyen el único ejemplo claramente documentado del procesado del enriado en aguas estancadas.

\section{SECUENCIA ESTRATIGRÁFICA}

El momento más antiguo documentado en el sondeo de la torre formada por el muro semicircular 111 (mera prolongación de la muralla 


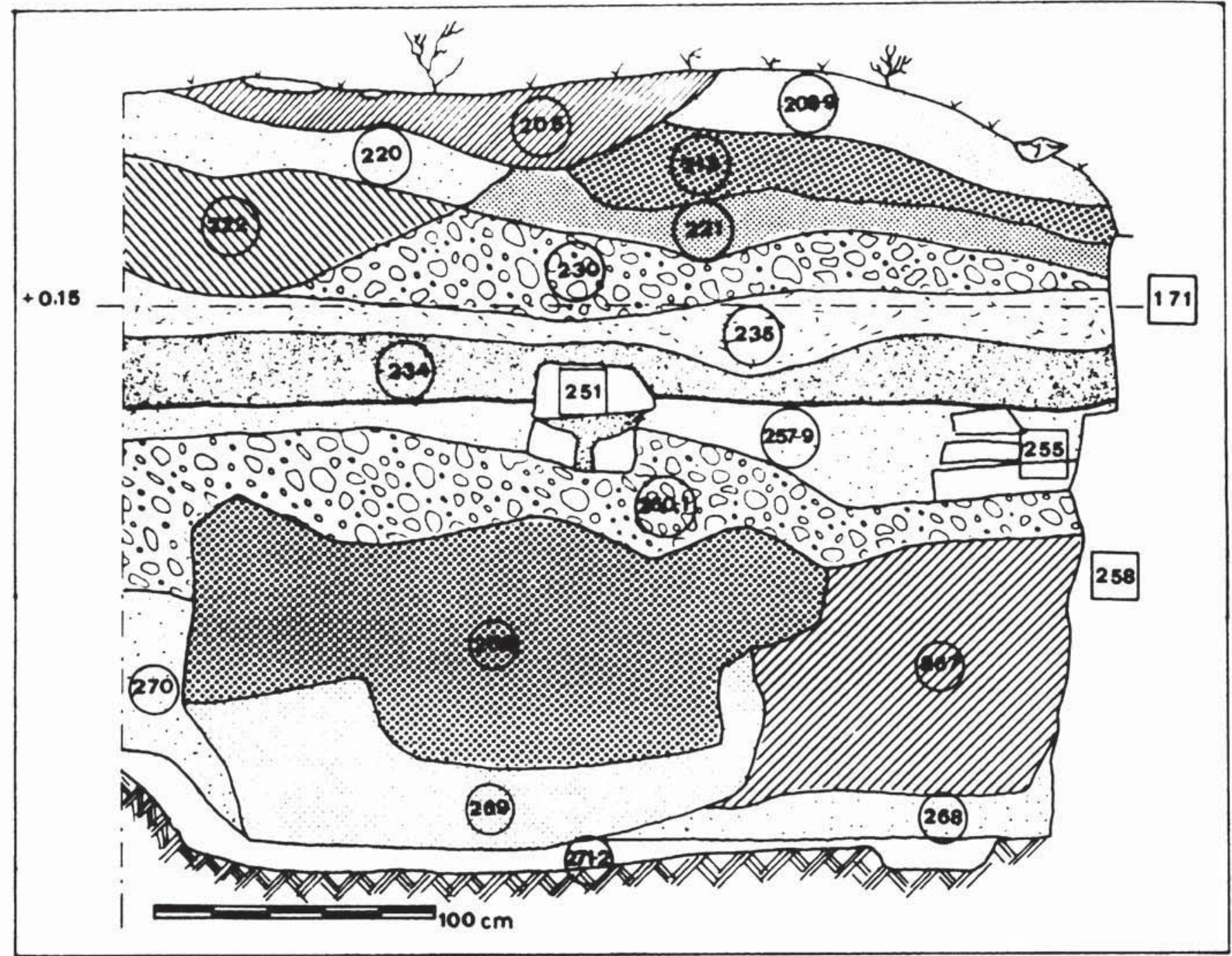

Fig. 2. Corte estratigráfico del sondeo realizado en el interior de la torre.

oeste del recinto fortificado) y el muro rectilíneo 258 que cierra el semicírculo es su propia construcción (Fig. 2). Como ya es usual en las edificaciones del yacimiento que nos ocupa, asienta directamente sobre la roca, sin ningún tipo de cimentación, con todo lo que ello implica a nivel de posibilidades de fechación. Los niveles designados como U.E. 271 y 272 corresponden al nivel de uso de la estructura, son de escasa potencia, con poco material mueble que, por otra parte, no es significativo cronológicamente hablando. Este horizonte de uso es contemporáneo al de las estructuras del taller propiamente dichas, cuyo sedimento arqueológico comentaremos más adelante.

A continuación documentamos en este sondeo de la torre un potente horizonte de derrumbe ( U.Es. $260=261,264,265,266,267,268$,
269 Y 270) resultado de la ruina repentina de toda su superestructura. A pesar de que las unidades estratigráficas que formaban dicho horizonte eran nítidamente diferenciables pertenecen, sin lugar a dudas, a un mismo momento cronológico: la distinción entre unas y otras se origina por un proceso deposicional diferencial de los diversos materiales constructivos que formaban parte de la estructura, fundamentalmente, arcilla, adobes, argamasa y, en menor cantidad, piedra.

Sobre este horizonte de derrumbe, se documenta un acondicionamiento para la reutilización de la estructura formado por una nivelación (U.E. $257=259$ ), la colocación de dos posibles bases para soporte de la cubierta (U.Es. 248 y 251), la construcción de dos bancos corridos (U.Es. 254 y 255 ) cuya finalidad fuera 
posiblemente reforzar los muros de la torre ! una remodelación y reconstrucción de la torre que pone de manifiesto la construcción de un nuevo muro de piedra (U.E. 171) que asienta sobre el de la fase anterior (U.E. 258 y $3(09)$ ). aunque corrigiendo levemente su trazado. El pavimento de tierra apisonada 240 ) corresponde a esta reutilización. Un nuevo horizonte de derrumbe-colmatación (U.Es. 208-209, 213, 220) a 222,233 a 235 y 238 ) marca el abandono definitivo de la estructura defensiva.

Las paredes y estructuras que conforman los ámbitos 6 y 7 del taller fueron construidas. al igual que las que definen el perímetro de la torre, directamente sobre la roca sin trinchera de cimentación. La edificación de estas habitaciones en un extremo del recinto fortificado, $y$ en el punto de inflexión donde la vertiente del cerro inicia la pendiente, hizo necesario nivelar el terreno con la aportación de tierras a fin de asentar el pavimento enlosado que cubre parte de la superficie del ámbito 7 para situarlo a una cota similar a la que presenta la roca en el resto de la habitación. Cabe mencionar, aún cuando no podamos aquí extendernos en este aspecto, los enterramientos infantiles localizados en el ángulo formado por los muros 111 y 309 , bajo el enlosado. Corresponden a tres individuos con edades de 4 a 6 meses, de 5,5 a 6,5 meses y de 7 a 9 meses de vida intrauterina, respectivamente, que fueron depositados sucesivamente en el mismo lugar. En cuanto al ámbito 6, las paredes que lo forman reposan, en la mitad norte de la estancia, sobre una banqueta corrida labrada en la roca calcárea, que se eleva entre 13 y $40 \mathrm{cms}$. en relación a la superficie central de la habitación, y que sin lugar a dudas fue retocada para tal finalidad. También, y de la misma manera que se ha identificado en el interior de la torre, la roca presenta una pendiente ligeramente descendiente hacia el NW, fruto de la basculación de las placas calcáreas que conforman el terreno, que en este caso fue salvado con un estrato de nivelación encima del cual se pavimentó a una cota aproximadamente horizontal $y$ uniforme.

Sobre los diversos pavimentos han sido individualizados los correspondientes niveles de uso en cada una de las estancias. Inmediatamente whre los niveles de uso se ha documentado un horizonte de derrumbe de gran potencia que supone la inutilizacion definitiva de las estructuras de la instalacion que nos ocupa y que corresponden al hundimiento de las paredes y cubiertas de manera unitaria. La destrucción del complejo se produjo indudablemente de forma repentina, a tenor de la homogeneidad en la composición de los materiales que contienen todos los estratos. esto es, adobes, argamasa, arcilla y piedras en menor medida. La inexistencia de estratos intermedios de aportación de tierras o rellenos y. sobre todo, el hecho mismo de la directa deposición del derrumbe sobre los niveles de uso, posibilitando la recuperación de los recipientes y materiales in situ, abogan esta afirmación. A grandes rasgos, podemos decir que el sedimento del ámbito 6 estaba compuesto básicamente por adobes enteros, fragmentados o deshechos al igual que gran parte del localizado en el interior de los depósitos de la estancia contigua. En el resto del ámbito 7. sin embargo, el derrumbe estaba constituído de manera preferente y casi exclusiva por una capa, muy potente (por término medio, entre 1 y $1,40 \mathrm{~m}$.), de argamasa de color blanco, con alto porcentaje de cal, y gran cantidad de cerámicas y otros materiales, así como también algunos adobes mezclados y dispersos.

Sobre este horizonte de derrumbe que cubre y oblitera totalmente la instalación para el tratamiento del lino se ha individualizado una nueva facies de ocupación paralelizable a la documentada en el interior de la torre, que consistió en la edificación de una nueva habitación en el espacio antes ocupado por el ámbito 7. A esta segunda fase constructiva corresponde el recrecimiento (U.E. 128 y 171) del muro rectilíneo que cerraba el ámbito por el norte y que lo separaba de la torre colindante, siendo así la única estructura reutilizada de la fase más antigua.

\section{LAS ESTRUCTURAS CONSTRUCTIVAS. MORFOLOGÍA Y TÉCNICA (Figs. 1 y 3)}

La torre es, como ya hemos dicho, de planta semicircular (medidas exteriores: 7,40 x 4,60 m.) y asienta directamente sobre la roca natural li- 
geramente retocada. Se trata de un banco calcáreo característico de la zona, donde las calcáreas tabulares, de probable origen lacustre, suelen formar plataformas planas, muy regulares. con un basculamiento de entre $5^{\circ}$ y $10^{\circ}$ hacia el N-NW (Carulla, 1991). La parte conservada en pie de los muros está hecha con piedra del lugar sin desbastar o groseramente desbastada formando bloques cuadrangulares irregulares unidos con arcilla. El muro rectilíneo que cierra la torre por el SE (U.E. $258=309$ ) tiene una altura conservada de $1.50 \mathrm{~m}$. La excavación del sondeo pone en evidencia que en esta primera fase constructiva los muros tenían una superestructura de adobe. Efectivamente, los potentes sedimentos correspondientes al primer horizonte de derrumbe muestran una extraordinaria abundancia de materiales constructivos, entre los cuales destacan los adobes hechos de arcilla y materia vegetal, paralelepípedos $(40 \mathrm{x}$ $14 \times 14 \mathrm{~cm}$., por término medio) y con digitaciones formando aspas múltiples o líneas paralelas situadas en sus caras no vistas para facilitar la adherencia. Las caras vistas presentan un revestimiento aplicado una vez construido el muro y hecho con una variedad de lutita de la zona, seleccionada y de textura fina (Labèrnia, 1993). En el curso de la excavación aparecieron tres pequeños fragmentos de este revestimiento pintados de rojo oscuro. Pero no es éste el único elemento constructivo del derrumbe que presenta interés: aparece, como ya hemos enunciado, gran cantidad de argamasa hecha con arcilla de baja pureza y conglomerado de cal (52,6\% de carbonato cálcico; Labèrnia, 1993). Este material forma casi exclusivamente las U.Es. 266 y 269 que suman una potencia de 0,96 a 1,20 metros, siendo pues una cantidad suficientemente significatica como para tratar de situarla en su contexto original. Diversas evidencias, que la brevedad de este artículo nos impide detallar, ponen de manifiesto que la argamasa en cuestión formaba parte de un piso superior con vigas de madera dispuestas transversalmente $(3,30 \mathrm{~m}$. de luz máxima). Así pues creemos que la torre tenía dos pisos de altura: el inferior con una puerta en el muro 258 que daba acceso al enlosado del ámbito 7 y el superior al cual se accedería por una escalera de mano. o desde una puerta, no conservada, que daría a la plataforma superior del recinto o bien de ambas formas. Dicho de otro modo, puesto que la torre se adosa por el NW a la plataforma superior del yacimiento y por la parte $\mathrm{SE}$ a la que denominamos plataforma 1 , situada a una cota inferior, se aprovechó dicha circunstancia para construirla, con relativamente poco esfuerzo, a un doble nivel, técnica constructiva que supone una optimización de la topografía y que. por otra parte, está ámpliamente documentada en el mundo ibérico.

El límite septentrional del ámbito 6 lo constituye un muro de piedras (U.E. 129), adosado longitudinalmente al paramento interno del lienzo de muralla que une dos de las torres del recinto fortificado (U.E. 174), el cual fue edificado unitariamente con los que de manera perpendicular conforman los límites este y oeste del mismo (U.Es. 136 y 170). Todos los muros están construídos con aparejo irregular de piedras de distintos tamaños sin desbastar o ligeramente retocadas unidas con barro o en seco y se conservan a una altura que oscila entre $0,70 \mathrm{y}$ $0,90 \mathrm{~m}$. A tenor de la gran cantidad de adobes exhumados en el derrumbe interior del ámbito, algunos con revestimiento de arcilla más fina y blancuzca en alguna de sus caras, se puede deducir que estas paredes debían tener además una elevación hecha con estos materiales.

En cuanto al cierre del espacio por el sur, la existencia de un corte vertical en la roca de, al menos, $40 \mathrm{~cm}$. de altura hace suponer el límite de la habitación por este punto aunque también podría indicar un pronunciado cambio de cota dentro de la misma estancia de modo que definiría un espacio a dos niveles, solución muy habitual en la arquitectura de los poblados ibéricos asentados sobre relieves en pendiente, entre los cuales uno de los ejemplos más paradigmáticos lo constituye San Antonio de Calaceite, a unos $20 \mathrm{~km}$. al oeste del Coll del Moro. De forma provisional y como hipótesis de trabajo, nos decantamos por esta interpretación de la pieza a dos niveles, extremo que deberá ser necesariamente contrastado en futuras campañas de excavación.

La habitación resultante a tenor de los límites mencionados es de planta rectangular deci- 


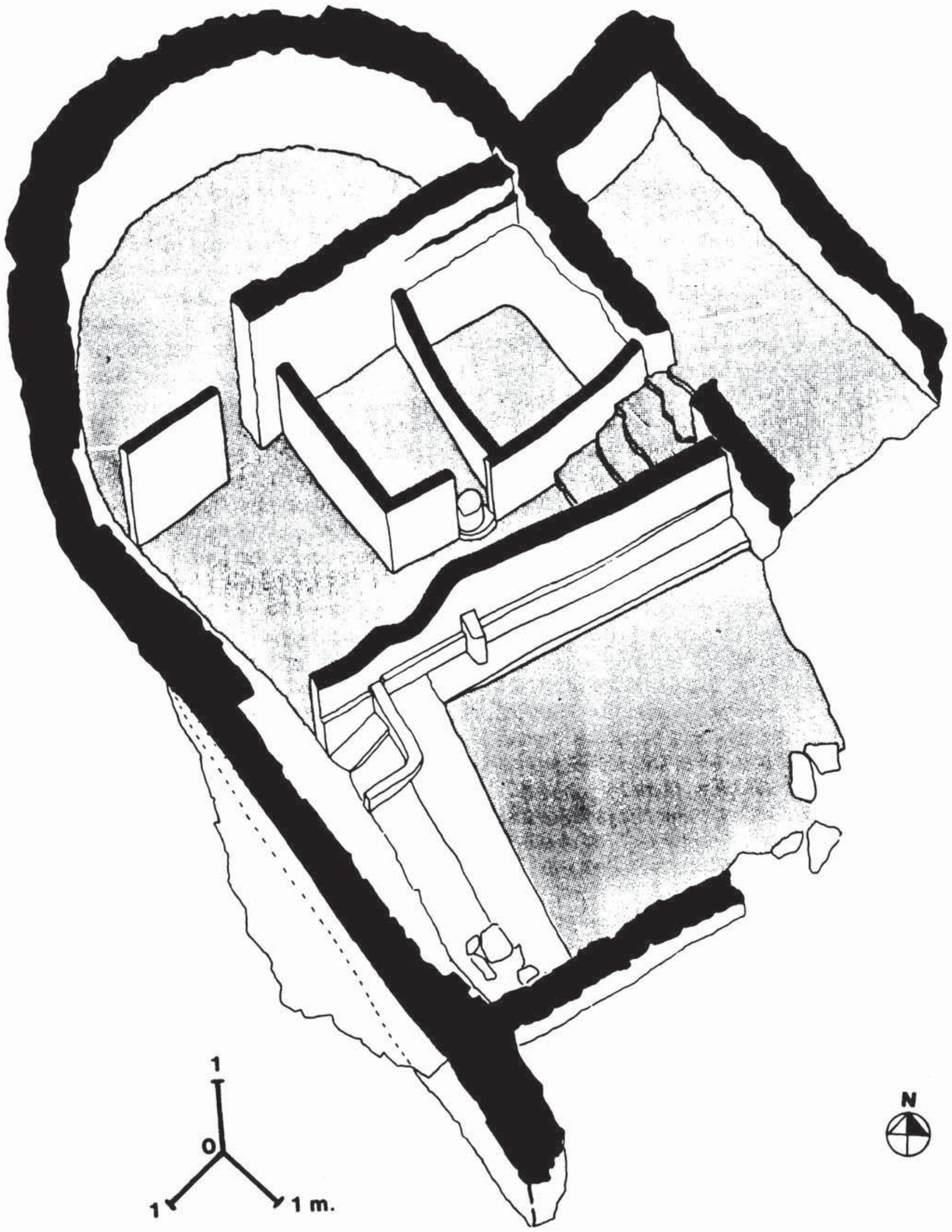

Fig. 3. P'rrspectiva del conjunto realizada a partir del estado conservado de los restos. 
didamente alargada $(2.20$ a 2.41$) \mathrm{m} . \times 5.40$ a 5.80 $\mathrm{m})$. Esta pavimentada con una capa de arcilla endurecida que no se documenta homogéneamente en toda la superficie puesto que en algunos puntos aflora ya la roca, y en su tercio norte se ubica un hogar circular de cierta entidad y dimensiones (U.E. 286), que constituye el único elemento constructivo documentado en el interior. La estructura de combustión está configurada por una anilla de losas planas. la mayoria con una característica pátina producida por el uso y algunos cantos de río. definiendo un diámetro exterior máximo de 1.60$) \mathrm{m}$. Pocos indicios de su uso podemos deducir del escaso y poco significativo material exhumado del estrato de cenizas correspondiente al hogar. Su función debe más bien inferirse de su situación dentro del ámbito 6 y sobre todo de la imbricación y conexión física de éste en relación al ámbito contiguo, el de los depósitos para enriar lino. Desde la estancia descrita se accede, por una puerta practicada en el muro occidental (U.E. 301), al ámbito 7, cuyo pavimento se halla a una cota inferior, por lo que un cuerpo de escaleras de cuatro peldaños (U.E. 313) salva el desnivel existente entre uno y otro. Este ámbito está definido, además, por la muralla oeste del recinto fortificado (U.E. 111), por el muro rectilíneo que cierra la torre semicircular colindante (U.E. $258=309$ ) y por una pared de adobes sobre un zócalo de piedras, que adosándose a la muralla, constituye el límite sur del mismo (U.E. 300). Los dos depósitos rectangulares y simétricos (aprox. 1,80 x 1,60 m.) fueron edificados unitariamente sobre la roca adosados a uno de los ángulos de la habitación. Su pavimento está constituído por piezas paralelepípedas (medidas: $25 \times 50 \times 13 / 15 \mathrm{cms})$ de arcilla sin cocer que fueron dispuestas con bastante regularidad sin romper junta (U.Es. 330 y 346 ). Las paredes sur, oeste y la medianera entre ambos (U.Es. 299,364 y 339) están hechas de adobes revestidos por una capa de arcilla más depurada y de color blanquecino. En el interior del depósito este se ha podido individualizar también una serie de losetas de piedra dispuestas horizontalmente y restos de yeso en las juntas del depósito que podrían corresponder a una refacción o refuerzo de este pavimento. Esta pileta tiene asimismo la particularidad de presentar gruesos revestimientos de arcilla forrando los paramentos de las paredes de piedra perimetrales a los que se adosa (U.Es. 302 y 303), solución no empleada en el depósito contíguo, donde sólo la fina capa de arcilla depurada y blanquecina impermeabiliza y aisla la estructura del paramento de piedra. Por el hecho de haberse podido localizar en dos puntos sendos tramos de los muros que definen los depósitos completamente vencidos, pero conservando todavía la conexión física de sus componentes, es posible restituir su altura original, de modo que se trataría de tabiques a media altura que se elevarían aproximadamente $1,10 \mathrm{~m}$. en relación a la cota del pavimento exterior. Respecto al resto del ámbito, el pavimento está constituído por la propia roca o por un enlosado de grandes piedras irregulares (U.E. 372), a menudo trabadas por otras más pequeñas, solución que se localiza allá donde la roca natural inicia la pendiente del espolón. En relación a la estructura compuesta por dos piedras superpuestas que está incorporada al muro de cierre sur de los depósitos creemos que debería ser la base de un elemento leñoso de soporte del segundo piso o de la cubierta. Esta hipótesis se apoya en el hecho de que este elemento se halla a una distancia equidistante entre los muros este y oeste del ámbito, probablemente con la finalidad de dividir la luz existente entre ellos $(6,50 \mathrm{~m}$.) y facilitar su cobertura.

\section{ANÁLISIS DE LOS MATERIALES}

Por lo que respecta al conjunto de los materiales, cabe destacar en primer lugar que muestran un predominio significativo, especialmente por lo que respecta a los niveles de la torre, de los grandes contenedores: tinajas del tipo llamado Ilduratin, ánforas y grandes jarras con borde de ánade. En relación con estos contenedores destacaremos la aparición de crecientes y piezas circulares planas, a veces, con elementos de prensión, que eran soportes y tapaderas, respectivamente, de los vasos citados. Este tipo de producciones son frecuentes en el área que nos ocupa con cronologías que van del siglo VI a.C. 
al siglo I a.C. (Belarte et alii. 1991: 59: Beltran Lloris, 1976: 254: Paris y Bardaviu, 1926: 27. fig 10 y 34: CVH Liria: lám. XIV, 2, 4, 6 y 8 : De Sus, 1984: 272, fig. 4: entre otros).

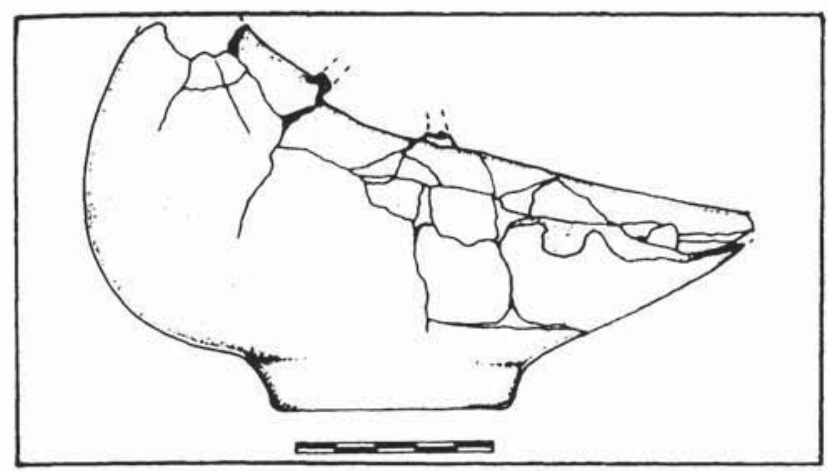

Fig. 4. Vaso ornitomorfo.

En cuanto al repertorio de formas documentadas son, en síntesis, además de las ya citadas: platos de borde entrante imitando formas del repertorio del barniz negro y realizados en cerámica oxidada a torno con decoración pintada, generalmente de bandas; páteras de cerámica de cocción oxidante, sin decorar, imitaciones también de las correspondientes al barniz negro; diversas variantes de ollas o urnas de perfiles de tipo globular, borde exvasado y factura grosera que suelen presentar en la inflexión del cuello, incisiones o cordones decorados; jarros con cuello de cocción oxidante y sin decoración; vasitos esquifoides de cocción oxidante, con o sin decoración pintada; un oenochoe de barniz rojo ilergeta; un kalathos con decoración pintada; un vaso ornitomorfo ( $i$ askos?) en forma de paloma, de cocción oxidante y sin decorar (Fig. 4); un vaso con pico vertedor inferior y un bol de barniz negro del taller de las pequeñas estampillas. Entre los materiales no cerámicos merecen ser destacados: 107 pesos de telar y un fragmento de vaina de espada, una contera, un mango de cuchillo, un fragmento de cuchillo y varios clavos, todo ello de hierro y procedente del sondeo de la torre.

Las decoraciones pintadas que aparecen en el conjunto de estos materiales ofrecen motivos geométricos y vegetales (en un caso que comentaremos a continuación también figurados). El motivo vegetal único que aparece es la hoja de hiedra con apéndices filiformes serpenteantes
(Fig. 5). Dicho motivo es propio en principio del estilo Elche-Archena desde donde se difunde a otros ámbitos, entre ellos el área ilergeta y el llamado estilo ornamental del Bajo Aragón. El motivo tiene una evolución que va de las hojas con filamentos delgados y serpenteantes como los nuestros, que aparecen en $\mathrm{Li}$ ria (CVH Liria: 106, motivos $227,231,232,237$ ) y se documentan a partir del siglo III en el País Valenciano (Mata. 1991: 129) y en yacimientos del área que nos ocupa como Tivissa (Vilaseca et alii, 1949: 33, láms. XIII,1 y XXI), hasta los filamentos muy barrocos que acaban transformándose en brácteas, que son propias y características del estilo ornamental del Bajo Aragón y tienen una magnífica representación en Azaila con cronologías de siglo II y primer cuarto del I a.C. (Beltran Lloris, 1976: 273, temas 83-91, fig. 72).

El kalathos (Fig. 6), exhumado en el curso del sondeo de la torre, tiene labio con engrosamiento vertical, cuerpo cilíndrico y asas horizontales. Se trata de un tipo presente en Azaila (Beltran Lloris, 1976: 232, fig. 58, núms. 961 , $963,975,976)$ y otros yacimientos aragoneses como Alloza y Tiro del Cañón de Alcañiz (Perales et alii, 1984: 228, núm. 33). Corresponde a los tipos B1-3 de la clasificación de Conde (1992) que se fechan en los últimos años del siglo III y la primera mitad del II. Kalathos con labio con engrosamiento vertical aparecen en el Bajo Aragón con cronologías de siglo II y I a.C., asociados, sin embargo, a decoraciones de hojas de hiedra evolucionadas. En nuestro caso, a parte de los materiales que aquí exponemos, contamos en el mismo yacimiento con otro fragmento del mismo tipo en un horizonte estratigráfico anterior a la forma Morel 68 de la campaniense A. La pieza de que tratamos se asocia, entre otros, a barniz rojo ilergeta y pequeñas estampillas, lo que, como comentaremos más detalladamente, nos obliga a fechar el kalathos en cuestión en la segunda mitad del siglo III a.C. La decoración de la pieza está dividida en tres registros horizontales, de los que el más completo es el superior dividido, a su vez, en cuatro metopas. Todos los elementos decorativos son de tipo geométrico (líneas rectas y onduladas verticales, círculos concéntricos, trazos parale- 


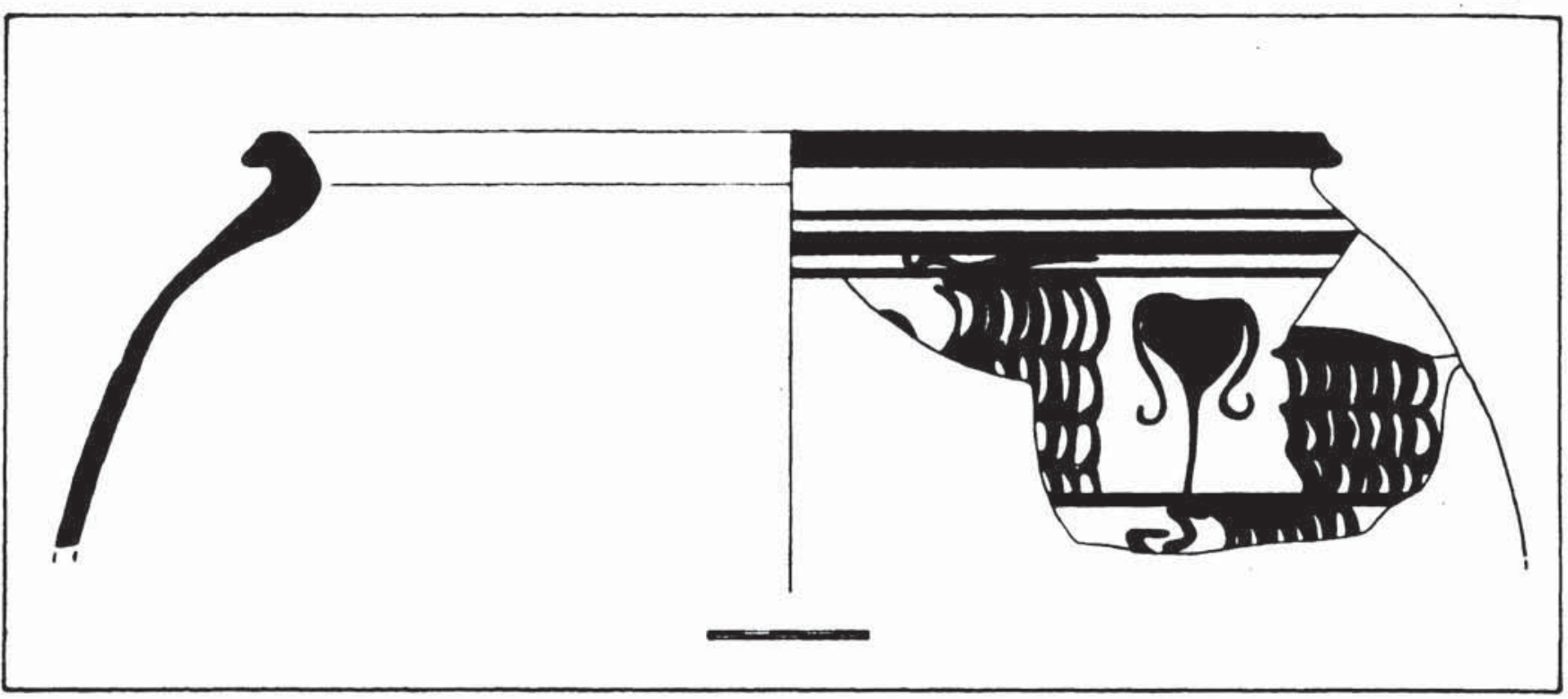

Fig. 5. Gran vaso con borde del tipo ánade y decoración pintada.

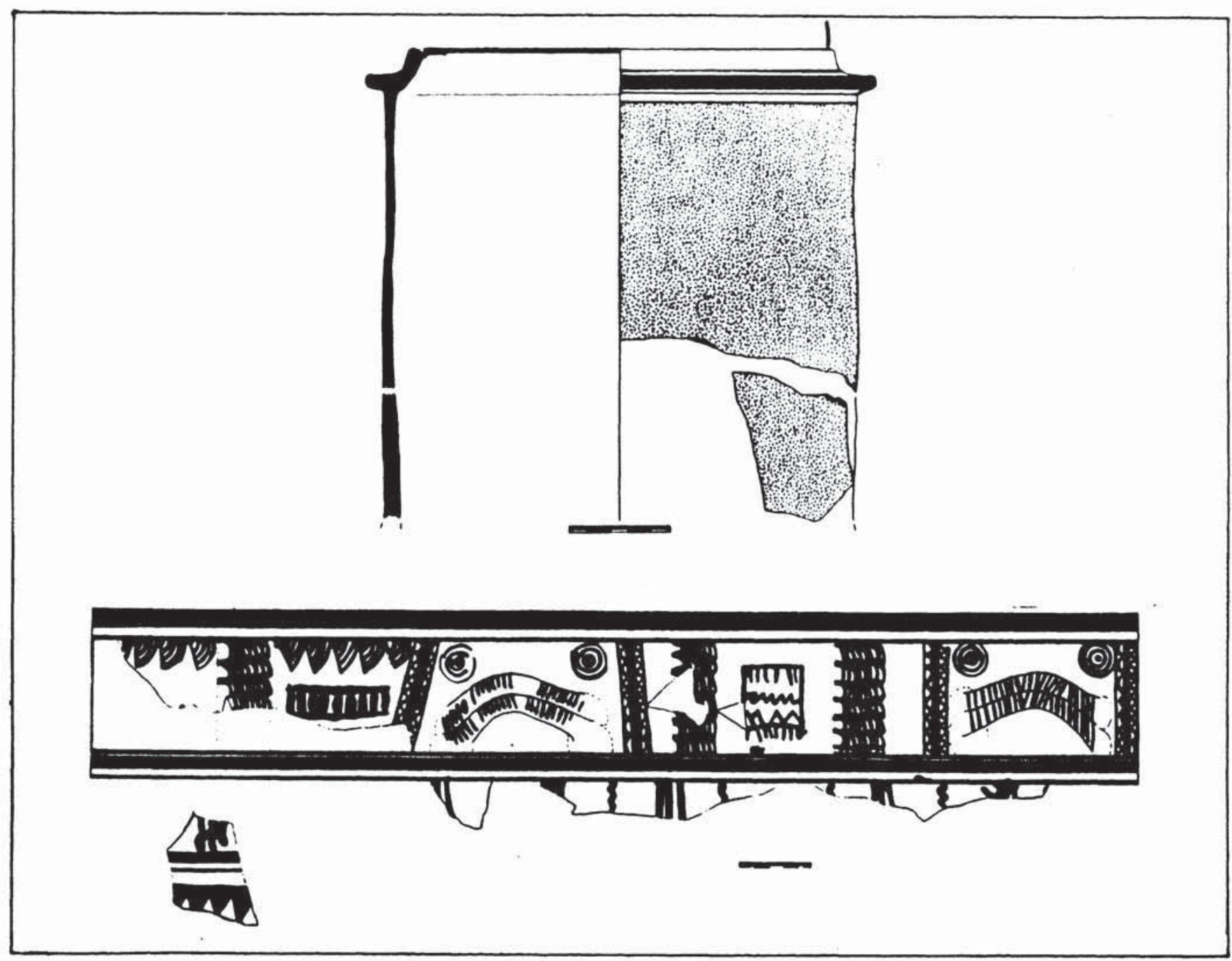

Fig. 6. Kalathos con decoración pintada y desarrollo de la misma.

T. P., 51, n. ${ }^{\circ} 2,1994$

(c) Consejo Superior de Investigaciones Científicas 
los, segmentos de círculo concéntricos, series de ondas o bucles verticales, dientes de lobo). a excepción de dos motivos figurados situados en el registro superior y uno de los cuales interpretamos como un posible telar vertical. Nos basamos para ello en la frecuencia de este tipo de representaciones en diversas culturas, pero esencialmente, en el mundo cerámico griego, y. sobre todo en la existencia de un paralelo formal en un fragmento de la Serreta de Alcoi (Visedo y Pascual, 1947: 57-59. fig. 1: Nördstrom. 1973: 166, fig. 47, 1, entre otros), sin contexto. donde se representa una escena con una mujer que sostiene lo que parece ser una lanzadera o huso que cuelga de un artefacto conservado solo parcialmente, aunque no cabe duda de que se trata de un telar. Desde un punto de vista iconográfico, vemos, pues, que las representaciones de telares son frecuentes en cerámicas de diferentes culturas, que no son desconocidas en el mundo decorativo ibérico y que el ejemplar que éste último ha proporcionado hasta ahora, el de la Serreta, puede ponerse en relación con la representación del Coll del Moro. Debido a lo grosero y poco detallado del elemento de que tratamos, quizá no hubiéramos planteado el tema de no ser el claro contexto del cual procede nuestra pieza: un conjunto arquitectónico donde se procedía al enriado del lino y donde, a juzgar por la serie de 107 pesos de telar en él hallada, también se tejía. El oenochoe de barniz rojo (Fig. 7) que acompañaba a esta pieza pertenece a la forma 1.1. de este tipo de producción y se fecha en el tercer cuarto y final del siglo III a.C. (Junyent, 1991: 10, 15).

Por lo que respecta al barniz negro correspondiente a este horizonte, cabe mencionar un ejemplar del taller de las pequeñas estampillas que se ha exhumado prácticamente entero en el derrumbe de la superestructura del ámbito 7 (Fig. 8). Se trata de una forma Lamb. 27, a medio camino entre las variantes a y b definidas por Morel (1969: 60-62), con el pie más bien recto como en el tipo a, aunque con el borde menos reentrante característico de la b. Las cuatro rosetas impresas en relieve en el fondo del recipiente tienen siete pétalos reseguidos exteriormente por una línea de realce más ténue y están separados por puntos (Morel, 1969:

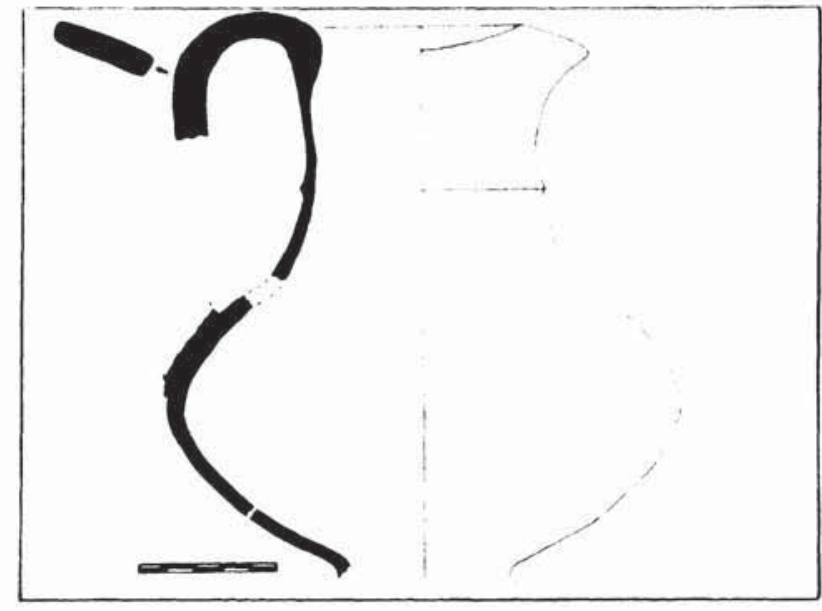

Fig. 7. Oenochoe de barniz rojo ilergeta.

fig.5, núm.8). El centro de las rosetas es un botón. La pasta es de color beige-anaranjado suave, relativamente blanda y en el corte presenta una superficie ligeramente rugosa. El barniz es negro, denso, rugoso en el interior y más brillante y fino en el exterior, estando el fondo externo reservado. En la Península Ibérica se conocen varios ejemplares de este taller procedentes de diversos yacimientos, desde Catalunya hasta Murcia (Sanmartí, 1973), y, hacia el interior, los puntos más avanzados se hallan en la zona ilergeta y en San Antonio de Calaceite (Sanmartí, 1973: 162-63, fig. 11,1).

Para finalizar, comentaremos brevemente las características del lote de 107 pesos de telar. Se trata en su mayoría de piezas enteras, alguna con desgastes o pequeñas fracturas. Sólo seis de ellas se conservan en menos de la mitad. Las formas predominantes son las rectangulares. 52 de las piezas tienen tanto los frontales como los laterales rectangulares, mientras que otras 20

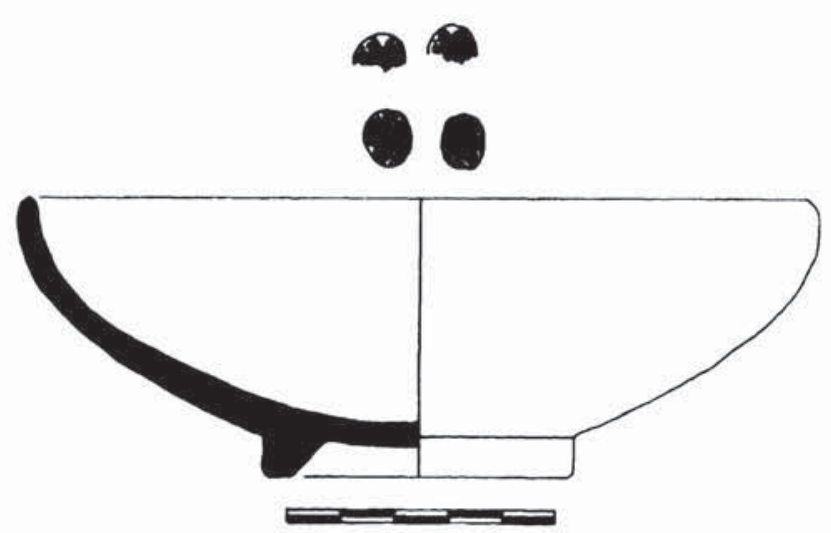

Fig. 8. Bol del taller de las pequeñas estampillas. 
tienen los frontales rectangulares, pero los laterales trapezoidales: los ejemplares restantes son de figura troncopiramidal o troncocónica en relación a sus frontales. Todas las piezas tienen una perforación, excepción hecha de cinco de ellas que presentan dos. Las pastas son. por lo general. depuradas y compactas. con cocción a fuego oxidante y superficies alisadas o bien tratadas con engobes arcillosos a la aguada. El conjunto ofrece diversos tipos de decoración: acanalada, incisa e impresa (Fig. 9). Nueve de las piezas están decoradas con acanaladuras anchas y poco profundas que rodean los frontales. laterales y cúspides, formando figuras cuadrangulares. Cinco de ellas tienen, a la vez, aspas incisas en sus frontales y una tres registros en la cúspide delimitados por líneas incisas y con sen-
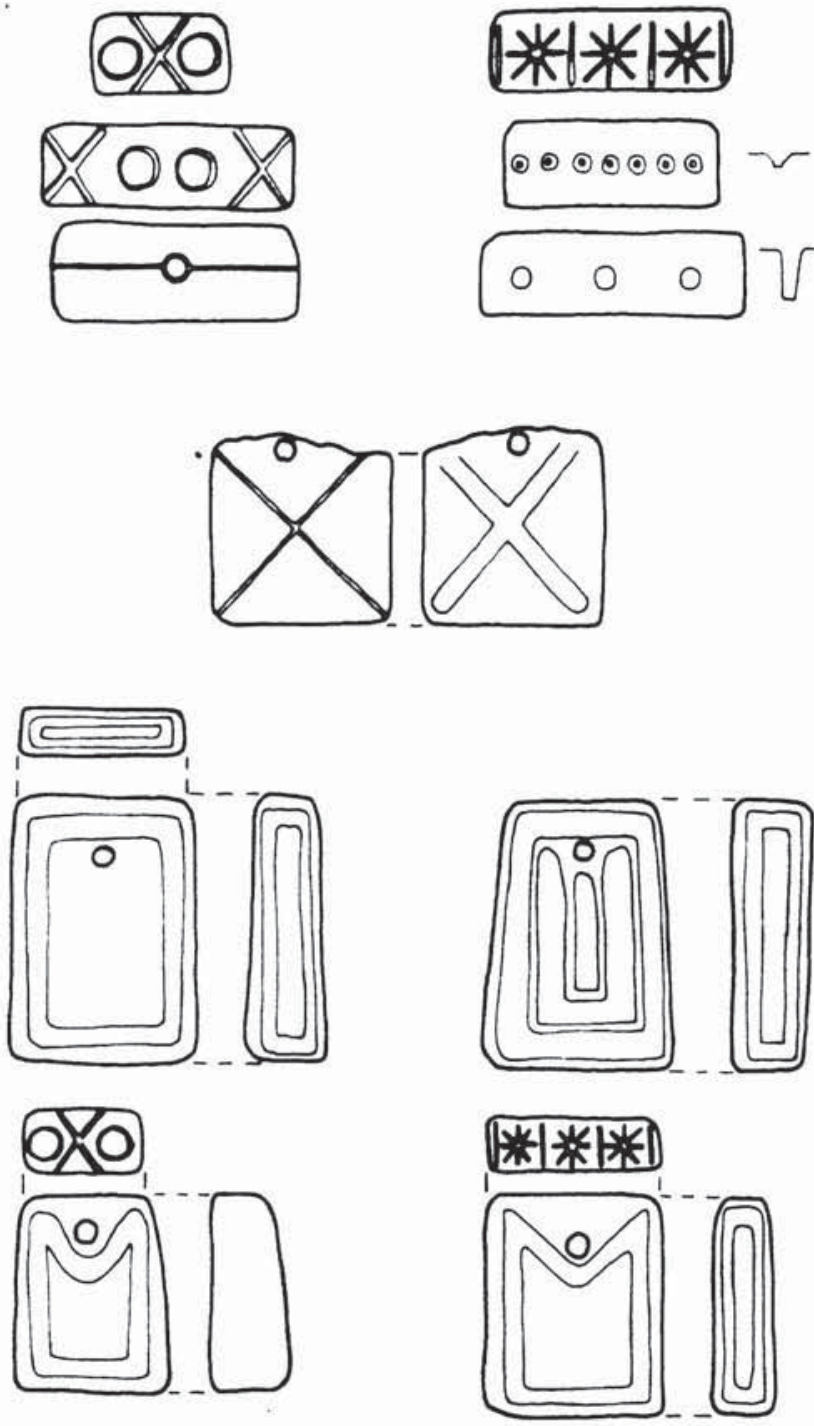

Fig. 9. Tabla de tipos decorativos del conjunto de pesos de telar. dos asteriscos en ellos. Diecinueve ejemplares presentan impresiones de puntos troncocónicos o, en un caso. cónicos, poco profundos que aparecen alineados en las cúspides en cantidades que oscilan entre 3 y 11 . Finalmente, hay 31 ejemplares con decoración incisa que combina los signos " $\mathrm{X}$ " $\mathrm{y}$ "O", formando "OXO" en cuatro casos y "XOOX" en el resto. Los cuatro pesos de telar con "OXO" miden $8 \times 6 \times 3 \mathrm{~cm}$. y pesan $300,301,311$ y 324 gramos; se trata de un caso claro de relación tamaño-peso-decoración. o. quizá debamos decir. marca. El grupo con "XOOX" mide $12 \times 10 \times 4 \mathrm{~cm}$. y tiene un peso medio de 761 gramos (con una amplia variación entre 996 y 605 gramos).

\section{CONSIDERACIONES CRONOLÓGICAS}

Los materiales más significativos para la fechación del conjunto que nos ocupa son el bol de barniz negro, forma Lamb. 27, del taller de las pequeñas estampillas hallado en el derrumbe de la superestructura del ámbito de los depósitos y los motivos decorativos de la cerámica ibérica pintada, el kalathos atribuible al grupo B1-3 de la clasificación de Conde y el oenochoe de barniz rojo ilergeta recuperados en el derrumbe individualizado en el interior de la torre y paralelizable al primero.

En relación al kalathos pintado, a los motivos decorativos de hoja de hiedra de la cerámica ibérica pintada y al oenochoe de barniz rojo ilergeta hemos hecho ya las suficientes consideraciones. Recordemos solamente que las cerámicas pintadas y el kalathos pueden situarse a partir de la segunda mitad del siglo III a.C. y que el oenochoe de barniz rojo está bien fechado en otros contextos desde el tercer cuarto del siglo III a.C.

En cuanto a la producción y difusión del taller de las pequeñas estampillas, la cronología inicial propuesta por Morel (1969) durante la primera mitad del siglo III a.C., corroborada según parece por los hallazgos de la Península Ibérica (Sanmartí, 1973), ha sido posteriormente precisada hacia el $285 \pm$ a.C. (Morel, $1978,1980)$. Este autor admite, si bien con reservas, la posibilidad de unas producciones tar- 
días de mediados o de la segunda mitad del siglo III a.C., pero insiste en la difícil o ténue penetración de los productos itálicos en el sur de la Galia y la costa de Iberia durante este período marcado por la Primera y Segunda Guerra Púnica (Morel, 1978: 156 y 164-65).

Sea como sea, la coexistencia del bol citado con el oenochoe de barniz rojo ilergete no creemos que implique contradicción alguna en relación a sus respectivas cronologías, puesto que debemos considerar la más que probable perduración y uso de determinadas piezas, especialmente las de calidad como nuestro ejemplar de barniz negro, más allá de su estricto período de producción y comercialización directa. En ambos casos se trata de recipientes que estuvieron en uso hasta la destrucción del complejo, puesto que se hallaron, aunque fragmentados, prácticamente enteros y su rotura fue debida al mismo proceso de ruina, tal como se aprecia en la gran mayoría de vasos exhumados, aplastados en su posición original o caídos desde el piso superior. Cabe destacar, asimismo, que el conjunto de los materiales, que no es lugar aquí de analizar pormenorizadamente, presenta una clara homogeneidad.

Por otro lado, la práctica inexistencia de campaniense A en los estratos de uso y subsiguiente derrumbe, que se reduce a un fragmento de asa de un pequeño vaso procedente del estrato de nivelación del ámbito 6 que por sus características bien podría tratarse de una importación temprana, aunque ex silentio, es un argumento de refuerzo que nos remite asimismo a un momento inmediatamente anterior a la eclosión comercial de las cerámicas campanianas del tipo $\mathbf{A}$.

En base a lo que hasta aquí llevamos expuesto, proponemos una datación para el momento final de uso y consiguiente destrucción del taller de lino y para el primer derrumbe de la torre, ambos simultáneos, en la segunda mitad del siglo III a.C. En cuanto a la fecha precisa de construcción nada podemos decir salvo que antecede, seguramente en poco tiempo, a la fecha citada, puesto que no nos lo permite el registro arqueológico: cimentación sobre la roca, ausencia de trincheras y estratos de nivelación de pavimentos prácticamente estériles y sin elementos fechables.

\section{CONCLUSIONES GENERALES}

Uno de los aspectos destacables de los resultados de la excavación de este conjunto es la fechación del encintado fortificado con torres semicirculares en un momento situable provisionalmente a mediados del siglo III a.C. o ya en su segunda mitad. La cuestión plantea un importante problema histórico claramente vinculado a aquellas relaciones entre Roma y Cartago que tuvieron como escenario la Península Ibérica y, más concretamente, la zona del Ebro, a partir del último cuarto del siglo III a.C. Tratar a fondo este aspecto rebasa con mucho el ámbito de este artículo puesto que ello obliga a afrontar unas circunstancias prolijas e insuficientemente conocidas y que, en cualquier caso, precisan de dataciones del registro arqueológico muy precisas, dataciones que la mayoría de los yacimientos de la zona aún no ofrecen.

Hechas estas advertencias, intentaremos hacer una aproximación muy global a la cuestión. La construcción del conjunto fortificado de que nos estamos ocupando, que transformó un hábitat defendido por una torre-atalaya en un recinto completamente fortificado, puede ponerse en relación, sin dificultades dignas de mención, con la época de cambios que vive la zona en la segunda mitad del siglo III a.C. El tratado del Ebro y el desembarco de Cneo Escipión en Ampurias no son más que los episodios más significativos de una situación que había tardado años en aflorar y desembocar finalmente en la Segunda Guerra Púnica. La actividad diplomática romana y, por supuesto, la presencia cartaginesa son anteriores. Los primeros debieron desplegar una notable actividad para constrarrestar la influencia cartaginesa, hasta el punto que ello llevó muy tempranamente a la formación de facciones prorromanas o procartaginesas entre los indígenas (Cabo y Vigil, 1975: 281). La voluntad de ambas partes de atacar al enemigo en su propio territorio tuvo como consecuencia largos preparativos, no sólo bélicos en sentido estricto. No es de extrañar, pues, que 
como resultado de esta situación general se erijan sistemas defensivos nuevos. hecho éste que no se documenta únicamente en nuestro yacimiento sino. muy probablemente, en otros del valle medio del Ebro (Burillo, 1991: 45). Es también indice de las circunstancias dichas el hallazgo hace ya años en el Coll del Moro de un posible tesorillo monetario fechado en $210-190$ a.C. (Abellá, 1978: Ripollés, 1982: 33).

El horizonte de derrumbe de la torre y el taller textil señala que el área no fue abandonada ni limpiada. como lo muestran los vasos enteros desplomados de los pisos superiores y algunas piezas in situ en los inferiores. En consecuencia. el derrumbe no afectó a una única estructura constructiva sino a un conjunto de ellas (si la magnitud del mismo fue aún mayor sólo podrán determinarlo futuras excavaciones) y, en segundo lugar, se produjo bruscamente. Creemos que tales evidencias autorizan a sugerir, a título de hipótesis, que el derrumbe, que, por otra parte, parece que se produce en un lapso de tiempo relativamente breve después de la construcción, tuvo una causa excepcional. Aunque, como ya hemos dicho, no es posible en el estado actual de conocimientos, establecer relación directa entre los hechos históricos referidos por las fuentes y los datos que de momento ha proporcionado el registro arqueológico, es muy plausible, a nuestro modo de ver, que esta relación exista y que próximas investigaciones puedan aclararla y matizarla.

El resultado de los análisis que se han llevado a cabo de los sedimentos orgánicos recogidos del fondo de los depósitos ha sido determinante para la interpretación global del complejo, puesto que ha permitido fijar la funcionalidad específica de estas singulares estructuras en el momento de su destrucción. La individualización de gran cantidad de fitolitos y fibras de lino (véase Anexo) dentro de las piletas, convenientemente impermeabilizadas y, por consiguiente, preparadas para contener líquido, permiten inferir que sirvieron para enriar lino, proceso que consiste en su maceración en agua a fin de poder separar y extraer de la planta las fibras apropiadas para la confección de tejidos. Por otro lado, la gran concentración de pondera en el mismo ámbito, probablemente caídos de un piso superior. nos remite otra vez a la actividad textil. Parece evidente, en consecuencia. que nos encontramos ante un recinto donde no sólo se preparaba una materia prima, el lino. para su posterior uso textil sino que también se realizaban otras operaciones relacionadas con esta actividad, como la propia manufactura de tejidos.

En cuanto al ámbito adyacente, si bien no podemos fijar su funcionalidad precisa por la ausencia de elementos muebles o estructurales suficientemente indicativos, parece lógico que de la conexión espacial de ambas piezas se pueda deducir que se trataba de una área de servicios auxiliares relacionados con el mismo proceso de tratamiento y transformación del lino. Hipotéticamente, pues, el hogar del ámbito 6 podría haber servido por ejemplo para calentar el agua de las piletas a fin de acelerar el proceso de putrefacción de los tallos de lino o bien para el teñido en caliente de las fibras, aunque de todo ello no existan trazas en el registro arqueológico. También como área de servicios auxiliares debemos calificar por el momento el espacio interior de la torre, además de la función defensiva que debía ejercer; a tenor de su conexión física con el taller debió estar vinculado al proceso textil. En cuanto a los grandes recipientes prácticamente enteros recuperados del derrumbe de la superestructura de la torre, nos inclinamos a pensar que provenían, como ya ha sido argumentado, de un piso superior, en el cual existiría un almacén de líquidos o de áridos, aunque por el momento no atisbamos relación posible con las necesidades del proceso de transformación del lino.

Respecto a las características de la segunda planta, sólo cabe añadir que el potente derrumbe depositado sobre los niveles de uso y compuesto casi exclusivamente por argamasa y vasos enteros pero fragmentados, hallado tanto en el interior de la torre como del ámbito $7 \mathrm{y}$ que, a nuestro entender, podría ser indicativo de un piso superior, no existía contrariamente en el derrumbe del ámbito 6, donde sólo se hallaron nódulos dispersos de este material sin constituir en absoluto un estrato similar al de los otros dos espacios. Esta distribución diferencial podría sugerir que este ámbito disponía 
sólo de una planta baja. cosa que. por otro lado. facilitaria la salida de humos producidos por la combustion del hogar. Evidentemente, establecer las características de este segundo piso y de su cubierta. absolutamente destruidos, es una tarea árdua y compleja de la cual por el momento sólo podemos esbozar una aproximación a tenor de los escasos y remotos indicios que hemos presentado a lo largo de este trabajo.

Son bien conocidas las referencias de las fuentes clásicas a la calidad y producción de tejidos de lino en la Península Ibérica, especialmente de Saitabi, los alrededores de Ampurias y Tarragona (Castro, 1983-84: 97: Domínguez, 1986). Por otro lado, los testimonios arqueológicos de la actividad textil en general están ampliamente atestiguados en numerosos poblados por la frecuente localización de piezas identificadas como pesos de telar y también de fusayolas, aunque respecto a la producción y confección específica de tejidos de lino los vestigios son bastante más escasos. En algunos yacimientos se han encontrado restos de telas de lino o improntas de las mismas sobre recipientes cerámicos u objetos de metal (Castro, 1983-84: 98). si bien no se han podido identificar inequívocamente instrumentos o instalaciones destinados al tratamiento exclusivo de esta fibra. La excepcionalidad de las piletas de Coll del Moro, faltas hasta el momento de paralelos directos, frente a la evidencia de una notable producción de lino en la sociedad ibérica, lleva a suponer que de forma habitual su enriado debía llevarse a cabo en otros lugares, como podría ser, por ejemplo. en ríos (extremo éste que para el caso de Tarragona refieren las fuentes escritas), estanques o albercas destinadas a usos diversos, donde el hallazgo de trazas de este proceso resulta de muy difícil o imposible identificación.

Por otro lado, creemos probable que algunos depósitos de ciertos yacimientos pudieran haber servido para la misma finalidad, pero la falta de análisis de los sedimentos no ha permitido su precisa atribución funcional. Inversamente, tampoco podemos descartar que las piletas de Coll del Moro pudieran haber sido usadas para otros menesteres, quizás para el curtido de las pieles, el teñido de las fibras o telas, o para el enriado del cáñamo. Sea como sea, el hecho de que el tratamiento del lino y tal vez de otras materias. generase en este poblado una estructura arquitectónica especifica podría ser indicativo de una notable tecnificación y especialización por parte de la comunidad en estas manufacturas. Sin emhargo, $y$ hasta que nuevas investigaciones no suministren más datos al respecto, no podemos, a partir de la morfologia de las piletas, fijar las características y el volumen de su producción. En este mismo sentido, cabe señalar que, si bien el lino es una planta que sólo permite una cosecha anual, también es cierto que puede ser almacenada, con lo cual las operaciones de enriado podrían sucederse repetidamente a lo largo del año, de modo que cualquier estimación de volumen está sujeta a una variable de frecuencia totalmente desconocida. Por otro lado, el hecho de que hasta el momento sólo se haya excavado una pequeña parte del poblado del Coll del Moro, que correspondería mayoritariamente a un complejo de estructuras defensivas, impide el conocimiento general de su organización urbanística, cosa que tal vez podría suministrar información sobre la magnitud y alcance de la producción o el uso social de estas instalaciones textiles. Así, quizás la generalización de los talleres en otras unidades del poblado o su excepcionalidad dentro del conjunto del asentamiento, su vinculación o autonomía respecto de las estructuras domésticas o de otra índole, sirvan de indicios para inferir, entre otras cuestiones, el destino de la producción, ya fuera el autoabastecimiento o el comercio exterior, o también para una aproximación al uso, comunitario o privatizado, de estas instalaciones.

\section{Agradecimientos}

Agradecemos a M.J. Conde sus interesantes comentarios y opiniones sobre el kalathos de la figura 6 .

\section{BIBLIOGRAFÍA}

Abellà, L. (1978): "Hallazgos monetarios en Coll del Moro de Gandesa". Numisma, XXVIII: 150-155.

Belarte, M.C., Mascort, M., Sanmarti, J. y SantacaNA, J. (1991): "El yacimiento del barranc de Gàfols 
(Ginestar, Ribera d'Ebre), un modelo protohistónico de colonizacion agricold". Boletin de la Real Sociedad Arqueológica Tarraconense, epeca V. 13: 5.5-67.

Bel tras LloRIs. M. (1976): Arqueologia e historia de las ciudades antiguas del Cabe:o de Alcala de Azaila (Teruel). Zaragoza.

Berges, M. y Firrtr. M. (1976): "La torre ibérica del Coll del Moro de Gandesa". Noticiario Arqueológico Hispanico. Prehistoria, 5: 393-398.

BURILLO. F. (1991): "Introducción a las fortificaciones de época ibérica en la margen derecha del Valle Medio del Ebro". Fortificacions. La problemàtica de l'lberic Ple (ss IV-III a.C.). Manresa: 37-50.

CABO. A. y Vigill. M. (1975): Condicionamientos geográficos. Edad Antigua. "Historia de España". I. Ed. Alfaguara. Madrid.

Carulla, N. (1991): "Estudi preliminar del substrat geològic, marc geomorfològic $\mathrm{i}$ àrees d'abastament del jaciment del Coll del Moro (Gandesa)". Informe inédito. Servei d'Arqueologia del Departament de Cultura de la Generalitat de Catalunya.

CASTRO, Z. (1983-84): "Notas sobre la problemática del tejido en la Península Ibérica". Kalathos, 3-4: 95-111. Teruel.

CONDE, M.J. (1992): "Una producció cerámica característica del món ibéric tardà: el kalathos "barret de copa". Fonaments, 8: 117-169. Barcelona.

CVH. Liria, Ballester, I.: Fletcher, D.: Pl.A, E.: JoRdA, F. y AlCÁCER, J. (1954): Cerámica del Cerro de San Miguel. Liria. C.S.I.C.-S.I.P. Madrid.

De Sus, M.L. y Perez, J.A. (1984): “Cabezo de la Bovina (Vinaceite, Teruel). Elementos de cultura material y economía". Kalathos, 3-4: 259-285. Teruel.

Dominguez, A.J. (1986): "La función económica de la ciudad griega de Emporion". VI Col.loqui Internacional d'Arqueologia de Puigcerdà (Puigcerdà, 1984): 193202. Puigcerdà.

JUNYENT, E. y Alastuey, A. (1991): "La vaixella ilergeta de vernís roig". Revista d'Arqueologia de Ponent, 1: 9. 50. Lleida.

LABÉRNIA, C. (1993): "Informe analític de diverses mostres del Coll del Moro". Laboratori del Consorci Lleidatà de Control. Col.legi d'Aparelladors, demarcació de Lleida. Informe inédito.

Mata, C. (1991): Los Villares. Trabajos Varios S.I.P., 88. Valencia.

Molas, D.; Rafel. N. y Puig, F. (1986)a: "El ritual funerari de la necrópolis del Coll del Moro (Gandesa, Terra Alta)". Cota Zero, 2: 48-52. Vic.

- (1986)b: "La necrópolis tumular del Coll del Moro, sector Maries, campanya de 1984 (Gandesa, Terra Alta)". Tribuna d'Arqueologia, 1985-86: 43-52. Barcelona.

MOREL, J.P. (1969): "L'atelier des petites estampilles". Melanges d'Archeologie et d'Histoire, LXXXI: 59-117. École Française de Rome. Paris.

- (1978): "A propos des céramiques campaniennes de France et d'Espagne". Archéologie en Languedoc, 1: 149-178.

- (1980): "La céramique campanienne: acquis et problémes". Céramiques héllenistiques et romaines. Univer- stte de Besançon. Centre de Recherches d'Historre Ancienne. Besançon: 85-122.

- (1981): Ceramique campanienne: les formes. Bibliothé que des Écoles Françaises d'Athénes et de Rome, fasc. 244. Paris.

Nordstrom. S. (1973): La ceramique peinte ibérique de la province d Alicante. Estocolmo.

PARIS. P. y BARDAIII, V. (1926): "Fouilles dans la region d'Alcañiz". Boletin de la Bibliotheque de l'École des Hautes Etudes Hispaniques, IX. 1. Paris.

Perales. M.P.; Picazo. J.V. y Sancho, A. (1984): "Tiro del Cañón (Alcañiz): Los materiales cerámicos". Kalathos, 3-4: 203-258. Teruel.

RAFFI. N. (1989): La necrópolis del Coll del Moro de Gandesa. Les estructures funeràries. Ajuntament de Tarra. gona. Tarragona.

- (1991): La necrópolis del Coll del Moro de Gandesa. Els materials. Diputació de Tarragona. Tarragona.

- (1993): Necrópolis del Coll del Moro, Gandesa, Terra Alta. Campanyes 1984 a 1987. Excavacions Arqueològiques a Catalunya, 12. Generalitat de Catalunya. Barcelona.

RAFEl, N. y BlasCO, M. (1991): "El recinte fortificat ibèric del Coll del Moro de Gandesa". Fortificacions. La problemàtica de l'Ibèric Ple (ss. IV-III a.C.). Manresa: 293-301.

- (1994): El Coll del Moro, un recinte ibèric fortificat. Campanyes 1982-83. Memòries d'Intervencions Arqueològiques a Catalunya. 8. Generalitat de Catalunya. Barcelona.

RAFEl, N. y HeRnández, G. (1992): "Pràctiques funeràries a la necròpolis del Coll del Moro (Gandesa, Terra Alta)". Revista d'Arqueologia de Ponent, 2: 37-57. Lleida.

RAFEL, N. y PUig, F. (1983): "Contribución al estudio de la arquitectura defensiva ibérica: El Coll del Moro de Gandesa". Actas del XVII Congreso Nacional de Arqueología (Logroño, 1983). Zaragoza: 603-610.

RipOLlés, P. P. (1982): La circulación monetaria en la Tarraconense mediterránea. Trabajos Varios del S.I.P.. 77. Valencia.

Sanmarti, E. (1973): "El taller de las pequeñas estampillas en la Península Ibérica". Ampurias, 35: 135-173. Barcelona.

- (1981): "Las cerámicas de barniz negro y su función delimitadora de los horizontes ibéricos tardíos (siglos IIII a.C.)". La baja época de la cultura ibérica (Madrid, 1979). Asociación Española de Amigos de la Arqueología. Madrid: 163-179.

Vilaseca, S., Serra-Rafols, J. de C. y Brull, L. (1949): Excavaciones del plan nacional en el Castellet de Bañolas de Tivisa (Tarragona). Informes y Memorias de la Comisaría General de Excavaciones Arqueológicas, 20.

ViSEDO, C. y PASCUAL, V. (1947): "Unos fragmentos cerámicos de la Serreta de Alcoy". Comunicaciones del S.I.P. al $1^{\circ}$ Congreso Arqueológico de Levante: 57-63. Valencia. 